\title{
INFLUENCE OF CONVENTIONAL VERSUS DIGITAL WORKFLOW ON MARGINAL FIT AND FRACTURE RESISTANCE OF DIFFERENT PRESSABLE OCCLUSAL VENEERS AFTER THERMOMECHANICAL FATIGUE LOADING
}

\author{
Shereen M. Elsayed* and Reham S. Elbasty**
}

\begin{abstract}
Objectives: The aim of the present study was to evaluate the marginal fit and the fracture resistance after thermomechanical fatigue of lithium disilicate occlusal veneers compared to zirconia lithium silicate occlusal veneers constructed using two techniques for wax pattern fabrication.

Methods: Thirty-two recently extracted non-carious maxillary molars were used in this study. The roots of all teeth were inserted with their long axes into epoxy resin moulds. All the teeth were prepared to receive all ceramic occlusal veneers. The non-retentive full-coverage circumferential design was chosen for the preparation of all selected teeth. All the prepared teeth were randomly divided into two equal groups $(n=16)$ according to the material used for fabrication of the occlusal veneer: Group I (e-max): Teeth received pressable lithium disilicate glass ceramic occlusal veneers. Group II (Celtra): Teeth received pressable zirconia-reinforced lithium silicate glass ceramic occlusal veneers. Each group was further subdivided into two equal subgroups $(n=8)$ according to the technique of construction of the wax pattern: Subgroup A (CAD/CAM): The wax pattern was constructed using CAD/CAM technique. Subgroup B (Conventional): The wax pattern was constructed by the manual conventional technique. CAD/CAM and conventional wax pattern were constructed according to manufacturer's instructions. The wax patterns of all groups and subgroups were sprued, invested and heat pressed to produce pressable lithium disilicate glass ceramic occlusal veneers for group I and pressable zirconia-reinforced lithium silicate glass ceramic occlusal veneers for group II. All occlusal veneers were cemented to their corresponding teeth using dual-polymerizing adhesive resin cement. Thermomechanical aging was performed on all the cemented occlusal veneers. Vertical marginal gap distance measurement was performed using USB Digital microscope. Fracture resistance testing was done using computer controlled Instron testing machine.
\end{abstract}

* Associate Professor, Fixed Prosthodontics Department, Faculty of Dentistry, Cairo University, Egypt. Associate Professor, Fixed Prosthodontics Division, Oral and Maxillofacial Department, Faculty of Dentistry, Umm Al-Qura University.

** Associate Professor, Fixed Prosthodontics Department, Faculty of Dentistry, Cairo University, Egypt. 
Results: The results of this study revealed that e.max processed by conventional wax technique recorded the highest vertical marginal gap mean values followed by Celtra processed by conventional wax technique then Celtra processed by CAD wax technique while e.max processed by CAD wax technique recorded the lowest mean values. The difference between subgroups was statistically non-significant as demonstrated by one-way ANOVA. Regarding the fracture resistance testing, It was found that e.max processed by conventional wax technique recorded the highest fracture resistance mean values followed by Celtra processed by conventional wax technique then e.max processed by CAD wax technique while Celtra processed by CAD wax technique recorded the lowest mean values. The difference between subgroups was statistically significant as demonstrated by one-way ANOVA $(\mathrm{P}=<0.0001<0.05)$. Tukey's post-hoc test showed non-significant $(\mathrm{p}>0.05)$ difference between ceramic groups processed by $\mathrm{CAD}$ or conventional wax technique.

Conclusions: Within the limitations of this study, it was concluded that: CAD/CAM constructed wax pattern presents a viable alternative option to conventional wax pattern fabrication for heatpressing restorations. Vertical marginal gap distance values of all groups were within the clinically acceptable range. The fracture resistance values of both tested materials used showed comparable results. The newly launched Celtra Press all-ceramic material revealed promising results in comparison to the gold standard e-max press all-ceramic material.

KEYWORDS: Pressable ceramics, Celtra press, IPS e-max press, Conventional wax pattern, CAD/CAM wax pattern, Thermomechanical aging, Marginal gap distance, Fracture resistance.

\section{INTRODUCTION}

Conservatism has always been described as a main concept and dream that prosthodontists are trying to reach within their restorations to fulfill the basic biological principles for tooth preparation. Currently, the minimally invasive approaches have been widely used to match this concept. ${ }^{(1)}$ These minimally invasive approaches may represent a promising treatment for patients introduced with problems related to occlusal contact such as caries or severe erosive wear resulting from gastroesophageal reflux disease, bulimia nervosa, and increased intake of acidic drinks. These troubles may result in damaging consequences of functional and esthetic complications including loss of vertical dimensions and pulpal involvement. (2-5) The prosthodontic treatment of these clinical cases is full of challenges. The conventional treatment modality for such hard tissue defects necessitates an additional removal of already debilitated tooth structure to receive full-coverage crowns. ${ }^{(6)}$ This option might cause more biological harmful consequences like postoperative hypersensitivity, loss of tooth vitality with subsequent need for endodontic treatment and more gingival inflammation caused by the subgingival margins of the full crowns. ${ }^{(7,89)}$ On the top of that, the clinical condition might have been complicated and the wear is compensated by tooth eruption keeping the occlusal vertical dimension the same and thus decreasing the space available for the restoration. ${ }^{(2)}$ Hence, this treatment modality might be considered inappropriate.

On the other hand, ceramic occlusal veneers offer a viable promising esthetic conservative alternative to restore the severely eroded teeth with minimum reduction of sound tooth structure to achieve a better balance between biological, functional and esthetic principles. ${ }^{(2,6,9,10,11)}$ Occlusal veneers consist of thin overlay coverage with non-retentive form. (13) The availability of ceramic materials that could be constructed in thin sections and still have high mechanical properties accompanied with improved bonding capabilities make the occlusal veneers a reliable successful prosthetic treatment option. Lithium disilicate glass ceramic is considered the strongest ceramic material that could meet these 
requirements. ${ }^{(1,14,15)}$ The introduction of the upgraded version of lithium disilicate; IPS e-max has made a great improvement in this ceramic material. ${ }^{(14)}$ The smaller, more uniformly distributed, interlocking needle-like lithium disilicate crystals which is the main constituent provide this ceramic a mechanical stability through hindering micro-crack propagation. $(1,14,16)$ This ceramic enables the prosthodontist to produce monolithic restoration with no veneering material and decreased functional drawbacks as chipping and fractures. ${ }^{(14)}$ Moreover, the bonding capability of lithium disilicate glass ceramic has been well documented giving it a combination of being strong ceramic and yet still etchable to achieve durable bonded strong restorations. ${ }^{(10,17,18)}$ In addition, this group of ceramics presented excellent optical properties and prevent excessive wear to the opposing teeth owing to its matching values to the enamel. ${ }^{(19,20,21)}$

Lithium disilicate glass ceramic restorations can be created by two processing techniques; $\mathrm{CAD} /$ $\mathrm{CAM}$ and heat pressing technique. ${ }^{(15)}$ Heat pressing technique represents a combination of injection molding method accompanied by conventional lost wax technique. (22) It was shown previously that fabrication process could influence the monolithic lithium disilicate glass ceramic restorations. (14) Heat pressed lithium disilicate restorations revealed improved mechanical properties with better flexure strength and fracture toughness than machinable lithium disilicate restorations. ${ }^{(14,23)}$

Lately, through the ongoing process of development of ceramic materials, the newly invented zirconia reinforced lithium silicate glass ceramics was introduced in the market. ${ }^{(22)}$ It was claimed that this new addition of $10 \%$ zirconia to lithium silicate yielded a new material category with higher fracture resistance and better esthetics. ${ }^{(11)}$ First, this category was introduced in the market in the form of machinable blocks either in fully crystallized state or with the need of short crystallization cycles. ${ }^{(22)}$ Later, it was launched in the form of homogenous industrially produced ingots named Celtra press to be constructed using heat pressing technique. ${ }^{(24,25)}$

Wax pattern fabrication is one of the steps needed during processing of heat pressed glass ceramics. Traditionally, wax pattern is fabricated manually by skilled dental technician using regular natural dental waxes. ${ }^{(26)}$ Instead, wax patterns can be constructed through more recent standardized process using CAD/CAM machines and millable superior synthetic wax and polymers. ${ }^{(27)}$ Accordingly, it was assumed that this advanced process may result in reduction of the manual processing errors and intensive laboratory steps. ${ }^{(28,29)}$

Marginal fit and fracture resistance are two common in-vitro parameters that represent the success and long-term survival rate of any new intra-oral material used as a new prosthetic option. An accurate marginal fit will prevent the exposure of cement to the oral environment which can result in subsequent percolation of bacteria, cement dissolution, caries, marginal discoloration and finally failure of the restoration. ${ }^{(28,30)}$

Owing to the brittle nature of lithium disilicate glass ceramics, it was always highlighted that the mechanical testing must be performed with cyclic fatigue loading and through a laboratory models that could give a good representation of the clinical environment. ${ }^{(31-34)}$ Therefore, the aim of this study was to evaluate the marginal fit and the fracture resistance after thermomechanical fatigue of lithium disilicate occlusal veneers compared to zirconia lithium silicate occlusal veneers constructed using two techniques for wax pattern fabrication. The first null hypothesis was that there would be no influence of the type of ceramic material and the technique of wax pattern construction on marginal fit of occlusal veneers after fatigue loading. The second null hypothesis was that there would be no influence of the type of ceramic material and the technique of wax pattern construction on the fracture resistance of occlusal veneers after fatigue loading. 


\section{MATERIALS AND METHODS}

Thirty-two recently extracted non-carious maxillary molars were selected and inspected meticulously to be free from any cracks or fractures. The teeth were cleaned from calculus remnants and stains using manual scaler and then stored in $0.1 \%$ thymol solution at room temperature not more than one month before the experiment. The dimensions of the teeth used in this study were measured using digital caliper (Mituotoyo, Japan) so that the teeth with similar dimensions buccolingually and mesiodistally were selected. The teeth with diverse dimensions were excluded from this study. The root portion of all teeth were covered with $0.2 \mathrm{~mm}$ thick gum resin acting as an artificial periodontal membrane. The roots of all teeth were then inserted with their long axes into epoxy resin installed in a cylindrical Teflon mould till $3 \mathrm{~mm}$ apical to their cemento-enamel junction.

\section{Teeth Preparation:}

All the teeth were prepared to receive ceramic occlusal veneers. The non-retentive full-coverage circumferential design was chosen for the preparation of all selected teeth. The occlusal surface was reduced $1-1.2 \mathrm{~mm}$ until reaching the dentin with a $120^{\circ}$ angles between buccal and lingual cusps. One $\mathrm{mm}$ axial surfaces preparation was done with $1 \mathrm{~mm}$ deep chamfer finish line created all around the tooth $2 \mathrm{~mm}$ apical to the prepared occlusal surface using tapered stone with rounded end with a noncutting guiding pin (Diamond instruments 856P, Drendel Zweiling Diamant GMBH, Germany) at- tached to a milling machine (Bego Paraskope, Germany) with copious amount of water coolant. A circumferential outer segment of the margin of all the prepared teeth was kept in enamel. The prepared teeth were finished and polished using fine-grit burs and abrasive rubber points (8856 P 314 018, Komet, 9608314 030, Komet). To ensure standardization, all the prepared teeth were done by the same operator. Fig. (1)

\section{Sample grouping}

All the prepared teeth were randomly divided into two equal groups $(n=16)$ according to the material used for the fabrication of the occlusal veneer:

Group I (e-max): Teeth received pressable lithium disilicate glass ceramic (IPS e-max press, Ivoclar, Vivadent, Schaan Liechtenstein) occlusal veneers.

Group II (Celtra): Teeth received pressable zirconia-reinforced lithium silicate glass ceramic (Celtra Press, Dentsply Sirona) occlusal veneers.

Each group was further subdivided into two equal subgroups $(n=8)$ according to the technique of construction of the wax pattern:

Subgroup A (CAD/CAM): The wax pattern was constructed using CAD/CAM technique.

Subgroup B (Conventional): The wax pattern was constructed by the manual conventional technique.

Sample grouping was presented in Table (1). Materials used, chemical composition and manufacturers name were presented in Table (2).

TABLE (1): Sample grouping.

\begin{tabular}{|l|c|c|}
\hline & $\begin{array}{c}\text { Group I } \\
\text { e-max occlusal veneer }\end{array}$ & $\begin{array}{c}\text { Group II } \\
\text { Celtra occlusal veneer }\end{array}$ \\
\hline Subgroup A & CAD/CAM wax pattern & CAD/CAM wax pattern \\
\hline Subgroup B & Conventional wax pattern & Conventional wax pattern \\
\hline
\end{tabular}


TABLE (2): Materials used, chemical composition and manufacturers name.

\begin{tabular}{|l|l|l|}
\hline Material & Chemical Composition & Manufacturer name \\
\hline IPS e-max press & $\begin{array}{l}\text { SiO2, Li2O, K2O, P2O5, ZrO2, ZnO, other } \\
\text { oxides and ceramic pigments }\end{array}$ & Ivoclar Vivadent, Schaan Liechtenstein \\
\hline Celtra press & $\begin{array}{l}\text { SiO2, Li2O, ZrO2, P2O5, Al2O3, K2O, } \\
\text { CeO2, other oxides and pigments }\end{array}$ & Dentsply;Konstanz, Germany \\
\hline Wax-On CAD Wax & $10 \%-80 \%$ Polyethylene wax \\
$10 \%-70 \%$ LD Polyethylene Homopol & On dent, Turkey \\
& $\begin{array}{l}1 \%-20 \% \text { Esther of hydrogenated } \\
\text { colophony constituents }\end{array}$ & \\
\hline Star Wax; Conventional Wax & $80 \%$ Hard Parrafin & Dentaurum, Germany \\
$15 \%$ bees wax & $5 \%$ Olive & \\
\hline Duo-Link Universal adhesive resin & $\begin{array}{l}\text { Dimethacrylates, Inorganic fillers, Ytter- } \\
\text { bement }\end{array}$ & Bium trifluoride, Catalysts and stabilizers, USA \\
Pigments. & \\
\hline
\end{tabular}

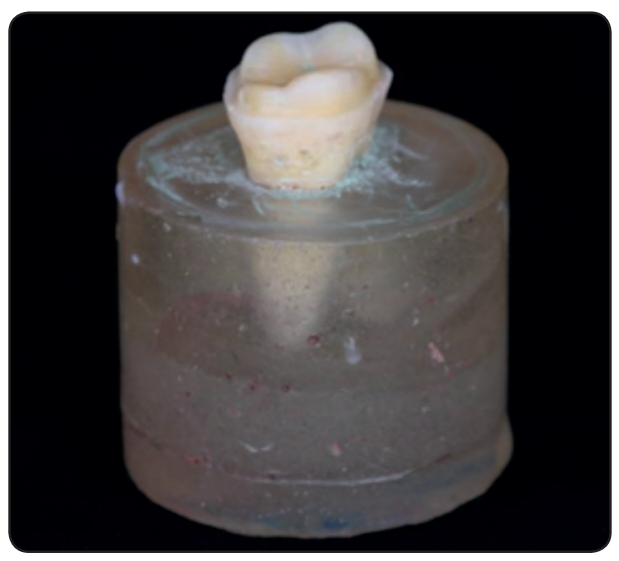

Fig. (1): Preparation design for occlusal veneer.

\section{CAD/CAM wax pattern fabrication (Fig.2,3):}

The prepared teeth of group (I), subgroup (A) and group (II), subgroup (A) were assigned for CAD/ CAM wax pattern technique. All the teeth were layered with spray powder (Renfert-Scanspray, Renfert, Germany) to be able to be scanned using CAD/CAM scanner (Medit Identica Hybrid 3D scanner, On dent, Turkey). The wax pattern design was created using CAD/CAM software (exocad DentalCAD, exocad GmbH, Germany). The design parameters were set to be $1 \mathrm{~mm}$ axial surface thickness, $1-1.2 \mathrm{~mm}$ occlusal surface thickness and

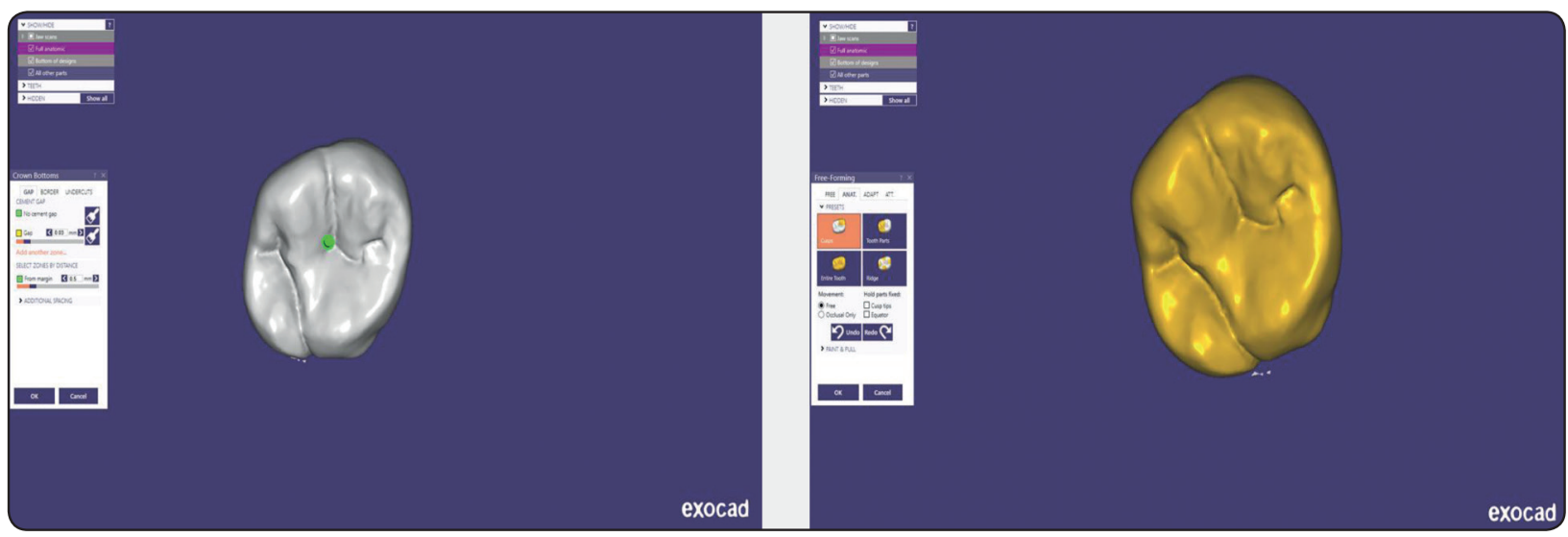

Fig. (2): Software designing for CAD/CAM wax pattern. 
$30 \mu \mathrm{m}$ cement space one mm away from the margin. The wax patterns for occlusal veneers were milled using 5-axis CAD/CAM milling machine (K5 Vhf, Vhf Camfacture AG, Germany) from CAD wax discs (Wax-On, On dent, Turkey).

\section{Conventional wax pattern fabrication (Fig.4):}

Regarding group (I) subgroup (B) and group (II) subgroup (B), wax patterns for occlusal veneers were fabricated by conventional manual technique. To standardize the thickness of wax patterns for both subgroups; CAD/CAM wax pattern and conventional wax pattern subgroups, a silicon index was constructed over one of the samples of the milled wax pattern of subgroup A and cut into two halves to be used during fabrication of the manual wax patterns. All teeth were coated with one coat of die spacer $1 \mathrm{~mm}$ away from the margin. Wax patterns were constructed conventionally using the add-on method. Modeling wax (Star Wax, Dentaurum, Germany) was heated by electric waxing unit, then added and designed until building the entire shape with the predetermined dimensions and thickness. The thickness of the wax patterns was confirmed using digital caliper. Lastly, margination of the wax pattern was done by reflowing of the marginal wax, addition of more wax at the margin, leaving it to cool and finally carving of the excess wax at the margin and burnishing it.

The wax patterns of all groups and subgroups were sprued and invested according to manufacturer's instructions. Occlusal veneers were fabricated using heat press technique where the wax was eliminated and the IPS e-max ceramic ingots (IPS e-max press LT, Ivoclar Vivadent AG, Schaan Liechtenstein) were pressed in the pressing furnace (Programat EP3000; Ivoclar Vivadent AG) to produce IPS e-max occlusal veneers for group I. Celtra Press ceramic ingots (Celtra Press, Dentsply Sirona) were pressed in the same furnace to produce occlusal veneers of group II. Devesting, finishing and polishing were done for occlusal veneers according to manufacturer's instructions. Fig. (5).

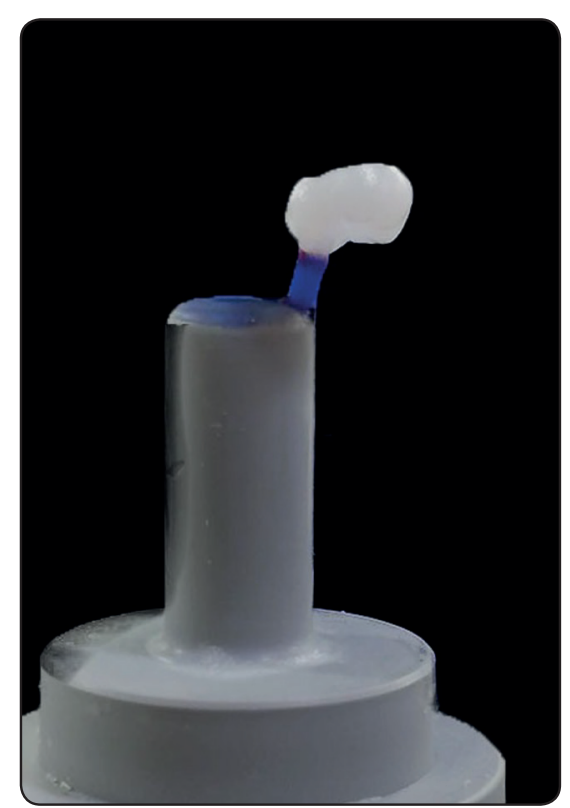

Fig. (3): Sprued CAD/CAM wax pattern in preparation for investing.

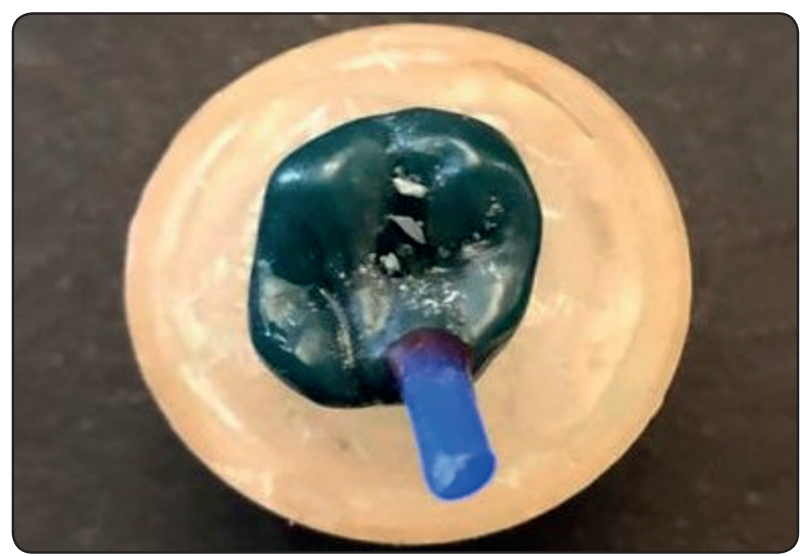

Fig. (4): Conventional wax pattern

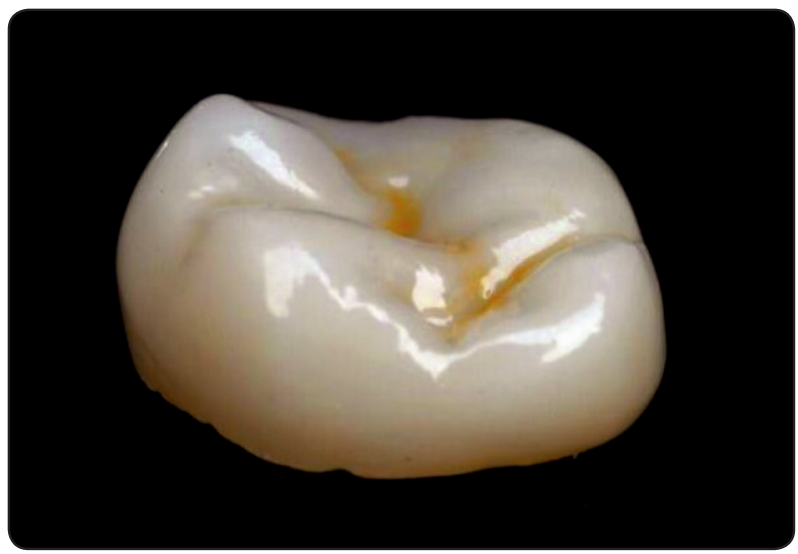

Fig. (5): Finished occlusal veneer. 


\section{Cementation of occlusal veneers:}

All the occlusal veneer samples for both groups were cleaned in ultrasonic bath for 3 minutes. Fluoride-free pumice was used to clean the prepared teeth for 15 seconds then thoroughly rinsed with water. The fitting surfaces of the occlusal veneers were treated with 5\% hydrofluoric acid (Ultra Porcelain Etch, Ultradent, Germany) for 20 seconds for group I and for 30 seconds for group II then thoroughly rinsed and dried with an air stream. A silane coupling agent (Ultradent Silane, Ultradent, Germany) was applied to the fitting surfaces of the occlusal veneers for both groups and allowed to soak for 60 seconds then blew dry with an air stream. All the prepared teeth were etched with $37 \%$ phosphoric acid etchant (Total Etch, Ivoclar Vivadent, Schaan, Liechtenstein) for 30 seconds on the enamel and 15 seconds on the dentin, then properly rinsed with water for 30 seconds. A bonding agent (ALLBOND Universal, Bisco, USA) was applied to the tooth surface, dried, then light cured for 10 seconds.

All the occlusal veneers were cemented to their corresponding teeth using dual-polymerizing adhesive resin cement (Duo-Link Universal, Bisco, USA) according to manufacturer' instructions. The cement was dispensed from the automix syringe, applied to the internal surface of the occlusal veneer and the occlusal veneer was seated over the prepared tooth. The restoration was kept in position by finger pressure for 10 minutes and the excess cement was carefully removed. A specially designed cementation device was applied over the occlusal veneer followed by light curing to each surface for 20 seconds using light curing unit (Mini LED, 1250 $\mathrm{mW} / \mathrm{cm} 2$, Satelec, Acteon).

\section{Thermo-Mechanical Aging:}

Mechanical aging was performed using a programmable logic-controlled equipment with four stations multimodal ROBOTA chewing simulator integrated with thermo-cyclic protocol operated on servo-motor (Model ACH-09075DC-T, AD-TECH TECHNOLOGY CO., LTD., GERMANY)

ROBOTA chewing simulator has four chambers simulating the vertical and horizontal movements simultaneously in the thermodynamic condition. Each of the chambers consists of an upper Jackob's chuck as hardened steel antagonist holder that can be tightened with a screw and a lower plastic holder in which the sample can be placed. A $5 \mathrm{Kg}$ weight which is comparable to $49 \mathrm{~N}$ of chewing force was applied. The test was repeated 75000 times to simulate the 6 months clinical chewing condition. ${ }^{(34)}$

\section{Vertical Marginal Gap Distance Measurement:}

A photograph was taken for each sample using Digital microscope containing built-in camera (U500X Digital Microscope, Guangdong, China). The microscope was linked to compatible computer and the magnification used was X45. Vertical marginal gap distance was measured using digital image analysis system (Image J 1.43U, National Institute of Health, USA). Photos of the margins were reported for each sample. For each photo, measurements were performed; three predetermined points were marked equidistant from each other all over the cervical circumference of each tooth surface. Fig. (6) Vertical marginal gap distance measurement was duplicated five times at each point. Data were gathered, arranged in tables and statistically analysed.

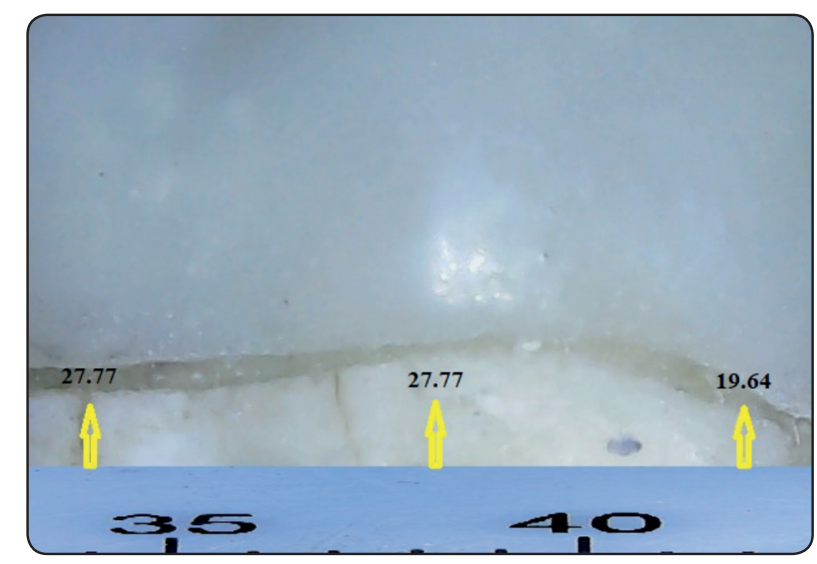

Fig. (6): Vertical marginal gap distance measurement. 


\section{Fracture Resistance Testing}

A computer-controlled material testing machine (Model 3345; Instron Industrial Products, Norwood, MA, USA) with a loadcell of $5 \mathrm{kN}$ was used to individually hold all samples and the data were reported via computer software (Instron ${ }^{\circledR}$ Bluehill Lite Software). Samples were tightened to the lower fixed part of testing machine by tightening screws. A compressive mode of load was directed occlusally by means of a metallic rod with $5.6 \mathrm{~mm}$ diameter spherical tip fastened to the upper movable part of the testing machine at $1 \mathrm{~mm} / \mathrm{min}$ cross-head speed. In order to minimize local force peaks transmission and ensure homogenous stress distribution, a tin foil sheet was placed in-between the sample and the applied load. The load at failure expressed by an audible fracture and verified by abrupt drop at load-deflection curve was reported using computer software (Bluehill Lite Software Instron ${ }^{\circledR}$ Instruments). The load needed to fracture was reported in Newton.

\section{RESULTS}

Graph Pad Instat (Graph Pad, Inc.) software for windows was used to analyse the results. A value of $\mathrm{P}<0.05$ was considered statistically significant. Continuous variables were presented as mean and standard deviation. After homogeneity of variance and normal distribution of errors had been proven, a two -way analysis of variance was performed to detect the effect of each variable. Student t-test was performed for compared pairs. Sample size $(n=8)$ was adequate to identify large effect sizes for main effects and pair-wise comparisons, with the satisfactory level of power set at $80 \%$ and a $95 \%$ confidence level.

\section{Vertical marginal gap distance testing:}

Descriptive statistics of vertical marginal gap distance $(\mu \mathrm{m})$ showing mean, standard deviation (SD) and 95\% confidence intervals (low and high) values for both ceramic groups as function of wax pattern technique are shown in table (3) and graphically illustrated in Fig. (7).

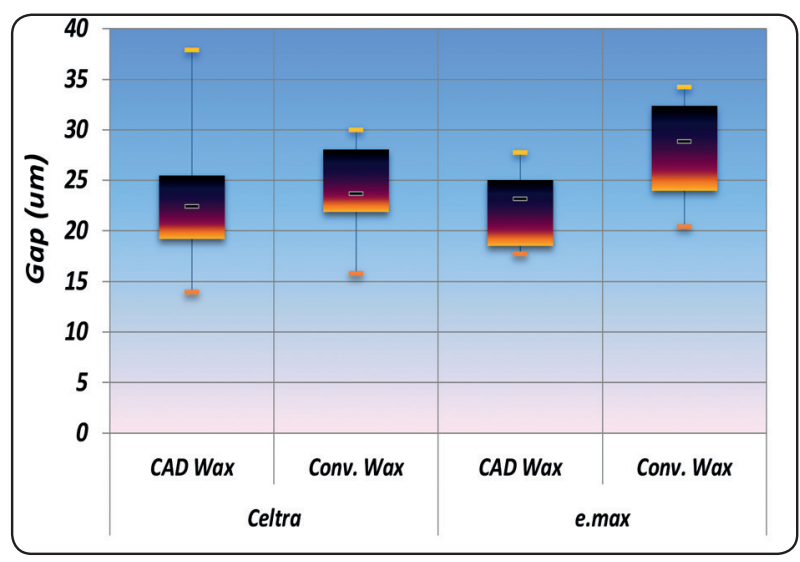

Fig. (7) Box plot of vertical marginal gap mean values for both groups with different wax pattern technique

TABLE (3): Descriptive statistics of vertical marginal gap results (Mean values \pm SDs) for both ceramic material groups as function of wax pattern technique.

\begin{tabular}{|c|c|c|c|c|c|}
\hline \multirow{2}{*}{\multicolumn{2}{|c|}{ Variables }} & \multirow{3}{*}{$\begin{array}{c}\begin{array}{c}\text { Mean } \pm \text { SD } \\
(\boldsymbol{\mu} \mathbf{m})\end{array} \\
23.19 \pm 6.4\end{array}$} & \multicolumn{2}{|c|}{$95 \% \mathrm{CI}$} & \multirow{2}{*}{$\begin{array}{c}\text { Statistics } \\
\text { Pvalue }\end{array}$} \\
\hline & & & Low & High & \\
\hline \multirow{2}{*}{ Celtra } & CAD & & 17.83 & 28.55 & \multirow{2}{*}{$0.7413 \mathrm{~ns}$} \\
\hline & Conv. & $24.11 \pm 4.3$ & 20.49 & 27.72 & \\
\hline \multirow{2}{*}{ e.max } & CAD & $22.04 \pm 3.3$ & 19.26 & 24.83 & \multirow{2}{*}{$0.009^{*}$} \\
\hline & Conv. & $28.07 \pm 4.5$ & 24.28 & 31.85 & \\
\hline
\end{tabular}

*; significant $(p<0.05)$

ns; non-significant $(p>0.05)$ 
It was found thate.max processed by conventional wax technique recorded the highest vertical marginal gap mean value followed by Celtra processed by conventional wax technique then Celtra processed by CAD wax technique while e.max processed by CAD wax technique recorded the lowest mean value. The difference between subgroups was statistically non-significant as demonstrated by oneway ANOVA $(\mathrm{P}=0.0891>0.05)$.

Regarding CAD wax pattern technique, it was found that Celtra group revealed statistically nonsignificant higher vertical marginal gap mean values than e.max group as shown by student t-test ( $\mathrm{p}=$ $0.661>0.05)$.

As for conventional wax pattern technique, it was found that e.max group showed statistically non-significant higher vertical marginal gap mean values than Celtra group as reported by student t-test $(\mathrm{p}=0.0952>0.05)$.

As regards the Celtra group, it was found that conventional wax pattern subgroup revealed statistically non-significant higher vertical marginal gap mean values than CAD one as shown by paired $\mathrm{t}$-test $(\mathrm{p}=0.7413>0.05)$.

Concerning e.max group, it was found that conventional wax pattern subgroup showed statistically significant higher vertical marginal gap mean values than CAD one as reported by paired t-test $(\mathrm{p}=0.009<0.05)$.

Total effect of ceramic material: Regardless to wax pattern technique totally, there was nonsignificant difference between both ceramic groups as shown by two-way ANOVA test $(\mathrm{p}=0.195>0.05)$.

Total effect of wax pattern technique: Irrespective of ceramic material group totally, it was found that wax pattern technique significantly influenced mean values as shown by two-way ANOVA test $(\mathrm{p}=0.003<0.05)$ where conventional wax pattern technique revealed higher mean values than $\mathrm{CAD}$ wax pattern technique.

\section{Fracture resistance testing}

Descriptive statistics of fracture resistance $(\mathrm{N})$ showing mean, standard deviation (SD) and 95\% confidence intervals (low and high) values for both ceramic groups as function of wax pattern technique are shown in table (4) and graphically illustrated in Fig. (8).

It was found that e.max processed by conventional wax technique recorded the highest fracture resistance mean values followed by Celtra processed by conventional wax technique then e.max processed by CAD wax technique while Celtra processed by $\mathrm{CAD}$ wax technique recorded the lowest mean values. The difference between subgroups was statistically significant as demonstrated by one-way ANOVA $(\mathrm{P}=<0.0001<0.05)$. Tukey's post-hoc test showed non-significant ( $\mathrm{p}>0.05)$ difference between ceramic groups processed by CAD or conventional wax technique.

Regarding CAD wax pattern technique, it was found that e.max group revealed statistically nonsignificant higher fracture resistance mean values than Celtra group as shown by student t-test $(\mathrm{p}=$ $0.4>0.05)$.

As for conventional wax pattern technique, it was found that e.max group showed statistically non-significant higher fracture resistance mean values than Celtra group as reported by student t-test $(\mathrm{p}=0.937>0.05)$.

As regards the Celtra group, it was found that conventional wax pattern subgroup revealed statistically significant higher fracture resistance mean values than $\mathrm{CAD}$ one as shown by paired t-test $(\mathrm{p}=0.0005<0.05)$.

Concerning e.max group, it was found that conventional wax pattern subgroup showed statistically significant higher fracture resistance mean values than CAD one as reported by paired t-test $(\mathrm{p}=0.0005<0.05)$. 
TABLE (4) Descriptive statistics of fracture resistance results (Mean values \pm SDs) for both ceramic material groups as function of wax pattern technique.

\begin{tabular}{|c|c|c|c|c|c|}
\hline \multirow{2}{*}{\multicolumn{2}{|c|}{ Variables }} & \multirow{3}{*}{$\begin{array}{c}\text { Mean } \pm \text { SD } \\
(\mathbf{N})\end{array}$} & \multicolumn{2}{|c|}{$95 \% \mathrm{CI}$} & \multirow{2}{*}{$\begin{array}{c}\text { Statistics } \\
\text { P value }\end{array}$} \\
\hline & & & Low & High & \\
\hline \multirow{2}{*}{ Celtra } & CAD & & 1760.2 & 2193.8 & \multirow{2}{*}{$0.0005^{*}$} \\
\hline & Conv. & $2912.6 \pm 522.4$ & 2475.8 & 3349.5 & \\
\hline \multirow{2}{*}{ e.max } & CAD & $2097.6 \pm 296.4$ & 1849.8 & 2345.3 & \multirow{2}{*}{$<0.0001 *$} \\
\hline & Conv. & $2928 \pm 179.02$ & 2778.6 & 3078 & \\
\hline
\end{tabular}

*; significant $(p<0.05)$

ns; non-significant ( $p>0.05)$

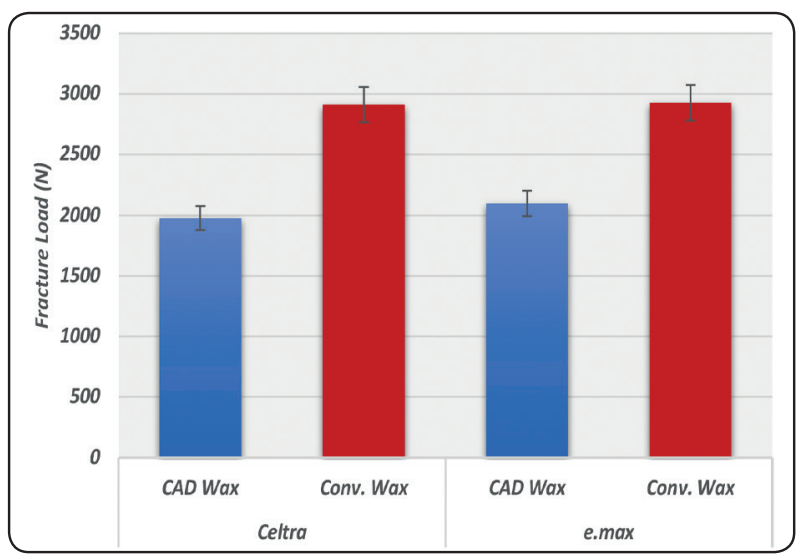

Fig. (8) Column chart of fracture resistance mean values for both groups with different wax pattern technique

Total effect of ceramic material: Regardless to wax pattern technique totally, there was nonsignificant difference between both ceramic groups as revealed by two-way ANOVA test $(\mathrm{p}=0.4494>0.05)$.

Total effect of wax pattern technique: Irrespective of ceramic material group totally, it was found that wax pattern technique significantly influenced mean values as shown by two-way ANOVA test $(\mathrm{p}=0.0001<0.05)$ where conventional wax pattern technique revealed higher mean values than $\mathrm{CAD}$ wax pattern technique.

\section{DISCUSSION}

Tabletop occlusal veneers are considered an attractive prosthetic option to restore function for teeth with severe occlusal wear as $40 \%$ of the prepared tooth structure could be preserved upon using these minimally invasive approaches. $(3,35)$ The key for the success of such restorations is the correct choice of the restorative material with its recommended thickness and its bonding durability. ${ }^{(3)}$ All these factors will influence the outcome of attaining higher strength and resistance for both tooth structure and restoration. ${ }^{(27,36,37)}$ In the present study, lithium disilicate glass ceramic was chosen as a restorative material owing to its matching properties to the requirements of such treatment prosthetic option. ${ }^{(19,38,39)}$ Applying an external pressure on the viscous glass ceramics at high temperature during sintering proved its ability to produce ceramic restorations with decreased porosity, high flexural strength and highly accurate marginal fit. ${ }^{(40-43)}$ Some studies concluded that lithium disilicate glass ceramic restorations exhibited better fracture resistance upon using heat pressing technique rather than CAD/CAM technique. ${ }^{(44,45)}$

Recently, high-strength zirconia reinforced lithium silicate glass ceramics are used with hotpressing technique to produce highly aesthetic allceramic restorations. This material was invented with lithium silicate main crystalline phase which 
is present in vitreous matrix and strengthened by zirconium dioxide crystals. Good mechanical properties and opalescent translucent properties are the main improved features of this material. Moreover, the outstanding polishability owing to the small crystal size in its material microstructure is considered as an additional benefit. ${ }^{(22,24)}$

Human natural teeth were used in this study as a bonding substrate due to the importance of assessing the tooth-cement-restoration complex achieving a better match to the clinical situation in relation to the bonding capabilities, fracture strength, and elastic properties. (46) The circumferential fullcoverage preparation design chosen in this study was in agreement with the preparation guidelines for minimally invasive restorations shown in previous studies. ${ }^{(13,15,47)}$ All the teeth were prepared using milling machine to ensure proper standardization for all the prepared teeth.

Currently, the availability of the CAD wax enables the clinicians to simplify the step of the wax pattern through designing the wax pattern by $\mathrm{CAD} /$ CAM software and then milling of the designed wax pattern by using acrylate polymers which burn out with no residue left resulting in pore-free pressing results. The high torsional stiffness and outstanding dimensional accuracy of the CAD wax result in excellent fit of the final restorations. Hence, the step of the wax pattern construction becomes faster and more standardized than handmade technique. ${ }^{(28)}$ Therefore, the authors showed their interest to examine the extent of the success of this simplified computer-controlled technique of construction of the pressable ceramics.

Marginal fit of an indirect restorations is considered a significant factor in assessing the success of the restoration. ${ }^{(48,49)}$ Decreased gingival inflammations, microleakage, recurrent caries and marginal discoloration are always accompanied by decreased marginal gaps. ${ }^{(28)}$ The gap measurements examined in this study concentrated on the vertical marginal gap distance which revealed the vertical distance from the margin of the restoration to the finish line of the preparation as defined previously in the literature. ${ }^{(50,51)}$ This measurement proved its reliability to evaluate the preciseness of the restoration fit. ${ }^{(52,53)}$

Theresults of this study revealed that conventional wax pattern technique had higher marginal gap distance than CAD/CAM wax pattern technique for both ceramic materials used. However, there was statistically significant difference between them in IPS e-max press group but no statistically significant difference in Celtra press group. Thus, the first null hypothesis was partially accepted. This may be attributed to the manual technique of conventional wax pattern in addition to the intrinsic limitations within the wax material itself. It was verified earlier that the process of wax pattern removal from the die to prepare for investing step might have resulted in an average marginal gap of $35 \mu \mathrm{m}$. ${ }^{(28)}$ The shiny surface and the color of the wax pattern were also factors that can cause difficulty in identification of small gaps at this area. The intrinsic imperfections of the natural waxes used in the construction of conventional wax patterns including fragility, elastic memory, high coefficient of thermal expansion and thermal sensitivity are also drawbacks that might have caused increased marginal gap values within this technique ${ }^{(54)}$.

Alternatively, construction of the wax pattern using CAD/ CAM technique might have resulted in some benefits. The use of synthetic waxes which are polymer mixtures made in the form of commercially prefabricated discs can produce more uniform composition and high-quality restorations. (28,55-57) Moreover, the automatic marginal recognition, the cement space selection option and the computer-based restoration designing gave the $\mathrm{CAD} / \mathrm{CAM}$ technique more reliability and simplicity. ${ }^{(58)}$ Nevertheless, some shortcomings have been reported with $\mathrm{CAD} / \mathrm{CAM}$ technique previously in the literature including the accuracy of the scanner, software and milling step specifically within the restorations with complex shape, deep 
grooves and internal angles as is the case with occlusal veneers. The size of the milling tool must be coordinative with the complexity of the restoration and its material properties otherwise fine details will not be precisely reproduced. ${ }^{(26)}$ It is worth mentioning that the CAD/CAM machine used in this study is 5-axis unit which revealed production of highly accurate restorations due to its ability to machine steep walls, undercuts and small angles from different directions. ${ }^{(59-61)}$ Therefore, avoiding the limitations stated in many previous invitro studies. ${ }^{(62-66)}$

It is well known that the marginal gap distance increases after final cementation due to cement film thickness. ${ }^{(67,68)}$ All the measurements of the marginal gap distance of this study were performed after cementation in order to mimic the real intraoral conditions. Thermomechanical aging was done as an essential step before marginal gap distance measurements so that the effect of the mechanical and thermal repeated cycles on the marginal adaptation would be reflected. The results of previous studies revealed that thermomechanical aging has a negative effect on the marginal gap distance of the restorations. ${ }^{(69,70)}$ All the marginal gap distance values shown in this study were within clinically acceptable range reported previously in many studies. ${ }^{(71-73)}$

Recently, there was a controversy regarding the reliability of the construction of thin allceramic occlusal veneer restorations although the manufacturers recommend a minimum required thickness to achieve optimum fracture resistance. ${ }^{(2,74,75)} \mathrm{Up}$ to date researches propose the reduction of thickness of all-ceramic occlusal veneers until $0.5-1 \mathrm{~mm}$ yet the restoration still can endure the normal masticatory forces. (75,76) This recommended thickness was utilised in this study to assess the fracture resistance of occlusal veneers. The influence of the dynamic loading on the fracture resistance value was examined owing to its significance on reproduction of clinically simulated fracture patterns especially with these newly introduced restorations. ${ }^{(34,77,78)}$
Besides, several studies ${ }^{(31-33)}$ mentioned that glass ceramics are very sensitive to fatigue failures throughout clinical service. On account of its inherent brittle nature, microcracks usually start at areas of stress concentration and continue under masticatory cycles until producing major flaws that could deteriorate the restoration, and upon reaching ultimate strength value, catastrophic fracture happens. ${ }^{(32)}$ A strong correlation between in vitro studies being presented in the form of fatigue testing and in vivo studies from randomised controlled clinical trials has been reported formerly in the literature. ${ }^{(79,80)}$ Many authors confirmed that modified laboratory examinations could simulate clinical scenarios upon controlling different experimental variable such as cycle numbers, wet environment, magnitude of the force and the abutment and antagonist materials. ${ }^{(34,81)}$ This will enable us to reach reliable data for newly introduced prosthetic solutions and materials within reasonable time frames other than the prolonged time given and the huge amount of data needed for in vivo studies to suggest innovative clinical guidelines. ${ }^{34,77)}$

In the current study, a total of 75,000 cycles of mechanical aging were performed. These cycles correspond to 6 months chewing simulation. ${ }^{(34)}$ It is of significance to mention that all the samples for all the groups survived all the cycles. In contrast to our understanding, some authors concluded that artificial aging has no significant influence on the ultimate fracture resistance of the samples during static fracture resistance testing despite the observed developed cracks in the samples after artificial aging. ${ }^{(82)}$ In another study, it was stated that the cracks will not influence the fracture resistance and they suggested that these microcracks developed in bonded ceramic restorations might have behaved similarly as the microcracks that can occur in enamel supported by dentine; this occurs naturally in human teeth without clinical failure. ${ }^{(3)}$

Regarding the fracture resistance testing, the results of the current study showed that there was no significant difference between IPS e-max press 
group and Celtra press group for both wax pattern techniques. This may be contributed to the increased interlocking of the platelet-shaped crystals of IPS e-max press achieving good mechanical properties. Similarly, the zirconia-reinforced lithium silicate category behaved the same as IPS e-max press. However, it was expected that Celtra press might have given higher fracture resistance values due to the addition of zirconia that acts as an additive which could positively influence the mechanical properties. The results of this study was in accordance with the findings of the in vitro study performed by Al-Akhali et al ${ }^{(1)}$ who concluded that there was no significant difference between lithium disilicate and zirconia-reinforced lithium silicate occlusal veneers after thermodynamic loading.

Furthermore, the influence of bonding techniques and the supporting substrate has been reported. In the current study, dentine was exposed by the tooth preparation through all surfaces, however a circumferential enamel margin has been reserved on the outer surface of the finish line. This might have guaranteed the stability of the tooth-cementrestoration complex through achieving excellent adhesive bond. Superior enamel bonding compared to dentine bonding was explained by Guess ${ }^{(83)}$ who stated that $0.5 \mathrm{~mm}$ thickness occlusal veneers bonded to enamel structure would have resulted in similar fracture resistance values to $2 \mathrm{~mm}$ thickness occlusal veneers bonded to dentine highlighting the positive influence of enamel bonding. Additionally, the elastic modulus mismatch between the lithium disilicate restoration and the bonding substrate whether enamel or dentine has shown a great influence on the load-bearing capacity. The small mismatch between lithium disilicate glass ceramic and enamel increases the fracture resistance of the bonded occlusal veneer. ${ }^{(10,19)}$

On the other hand, it was noticed from the results of this study that the conventional wax pattern technique revealed statistically significant higher mean fracture resistance values than $\mathrm{CAD} / \mathrm{CAM}$ wax pattern technique for both ceramic materials used, however, the authors could not reach any evidence based explanation to this finding and thus it needs further investigation. Hence, the second null hypothesis was partially accepted.

The results of the current study confirm that the mean fracture resistance values of all groups were beyond the normal masticatory forces of 600-900 N in the molar region. ${ }^{(84)}$

This study has some limitations. The use of natural teeth as a bonding substrate might have proposed a clinically mimicking scenario, however the variability among the natural teeth and the absence of dentinal fluids in the extracted teeth might have affected the results. Further in vitro studies on the performance of pressable lithium disilicate ceramics for occlusal veneers with reduced thickness under fatigue loading are recommended. Different bonding strategies with ultrathin occlusal veneers must be investigated so that the most conservative, less technique sensitive protocol could be presented as a clinical guideline. Finally, the controlled clinical trials are still indicated to evaluate the long-term survival rates of such new restorations.

Within the limitations of this study, it was concluded that:

1. $\mathrm{CAD} / \mathrm{CAM}$ constructed wax pattern presents a viable alternative option to conventional wax pattern fabrication for heat-pressing restorations.

2. Vertical marginal gap distance values of all groups were within the clinically acceptable range.

3. The fracture resistance values of both tested materials used showed comparable results.

4. Newly launched Celtra Press all-ceramic material revealed promising results in comparison to the gold standard e-max press all-ceramic material. 


\section{REFERENCES}

1. Al-Akhali M, Chaar MS, Elsayed A, Samran A, Kern M. Fracture resistance of ceramic and polymer-based occlusal veneer. Journal of Mechanical Behavior of Biomedical Materials 2017;74:245-250.

2. Sclichting LH, Maia HP, Baratieri LN, Magne P. Noveldesign ultra-thin CAD/CAM composite resin and ceramic occlusal veneers for the treatment of severe dental erosion. J Prosthet Dent 2011; 105:217-226.

3. Yazigi C, Kern M, Chaar MS. Influence of various bonding techniques on the fracture strength of thin CAD/CAM-fabricated occlusal glass-ceramic veneers. Journal of Mechanical Behavior of Biomedical Materials 2017; 75:504-511.

4. Ioannidis A, Muhlemann S, Ozcan M, Husler J, Hammerle C. Ultra-thin occlusal veneers bonded to enamel and made of ceramic or hybrid materials exhibit load-bearing capacities not different from conventional restorations. Journal of Mechanical Behavior of Biomedical Materials 2019; 90:433-440.

5. Egbert JS, Johnson AC, Tantbirojn D, Versluis A. Fracture strength of ultrathin occlusal veneers restorations made from CAD/CAM composite or hybrid ceramic materials. Oral Sci Int 2015; 12:53-58.

6. Maeder M, Pasic P, Ender A, Ozcan M, Benic G, Ioannidis A. Load-bearing capacities of ultra-thin occlusal veneers bonded to dentine. Journal of Mechanical Behavior of Biomedical Materials 2019; 95:165-171.

7. Pjetursson, B.E., Sailer, I., Zwahlen, M., Hammerle, C.H. A systematic review of the survival and complication rates of all-ceramic and metal-ceramic reconstructions after an observation period of at least 3 years. Part I: single crowns. Clin. Oral Implant Res 2007;18 (3):73-85.

8. Sailer, I., Pjetursson, B.E., Zwahlen, M., Hammerle, C.H. A systematic review of the survival and complication rates of all-ceramic and metal-ceramic reconstructions after an observation period of at least 3 years. Part II: fixed dental prostheses. Clin. Oral Implant. Res 2007;18 (3): 86-96.

9. Magne P, Schlichting LH, Maia HP, Baratieri LN. In vitro fatigue resistance of CAD/CAM composite resin and ceramic posterior occlusal veneers. J Prosthet Dent 2010; 104:149-157.

10. Heck K, Paterno H, Lederer A, Litzenburger F, Hickle R, Kunzelmann KH. Fatigue resistance of ultrathin CAD/ CAM ceramic and nanoceramic composite occlusal veneers. Dent Mater 2019;35:1370-1377.
11. Shaker A. Fracture strength of two overlay ceramic CAD/ CAM designs and regular glass-ceramic crowns: A comparative study. EDJ 2014;60:827-837.

12. VonMaltzahn NF, El Meniawy OI, Breitenbuecher N, Kohorst P, Stiesch M, Eisenburger M. Fracture strength of ceramic posterior occlusal veneers for functional rehabilitation of an abrasive dentition. Int J Prosthodont 2018; 31:451-452.

13. Angerame D, De Biasi M, Agostinetto M, Franzo A, Marchesi G. Influence of preparation designs on marginal adaptation and failure load of full coverage occlusal veneers after thermomechanical aging simulation. J Esthet Rest Dent 2019;31(3):1-24.

14. Zarone F, Ferrari M, Mangano FJ, Leone R, Sorentino R. "Digitally oriented materials": Focus on lithium disilicate ceramics. Int J Dent 2016; Article ID 9840594:1-10.

15. Emam ZN, Aleem NA. Influence of different materials and preparation designs on marginal adaptation and fracture resistance of $\mathrm{CAD} / \mathrm{CAM}$ fabricated occlusal veneers. EDJ 2020;66:1-14.

16. Oh SC, Dong JK, Luthy H, Scharer P. Strength and microstructure of IPS Empress 2 glass-ceramic after different treatments. Int. J. Prosthodont. 2000; 13:468- 472.

17. Magne P, Stanley K, Schlichting LH. Modeling of ultrathin occlusal veneers. Dent Mater 2012; 28:777-782.

18. Al-Akhali M, Kern M, Elsayed A, Samran A, Chaar MS. Influence of thermomechanical fatigue on the fracture strength of CAD-CAM-fabricated occlusal veneers. J Prosthet Dent 2019; 121: 644-650.

19. Ma L, Guess PC, Zhang Y. Load-bearing properties of minimal-invasive monolithic lithium disilicate and zirconia occlusal onlays: finite element and theoretical analyses. Dent Mater 2013; 29(7): 742-751.

20. Heffernan MJ, Aquilino SA, Diaz-Arnold AM, Haselton DR, Stanford CM, Vargas MA. Relative translucency of six all-ceramic systems.:Part I: core materials. J Prosthet Dent 2002; 88: 4-9.

21. Heffernan MJ, Aquilino SA, Diaz-Arnold AM, Haselton DR, Stanford CM, Vargas MA. Relative translucency of six all-ceramic systems.:Part II: core and veneer materials. J Prosthet Dent 2002; 88: 10-15.

22. Da Silva LH, De Lima E, De Paula Miranda RB, Favero SS, Lohbauer U, Cesar PF. Dental ceramics: a review of new materials and processing methods. Braz Oral Res. 2017; 31(e58):133-146. 
23. Uhler-Zemp PB, Olkel TV, Fischer K, Scientific Documentation IPS e.Max Press, Ivoclar Vivadent, Schaan, Liechtenstein, 2011.

24. Celtra Press, Dentsply Sirona, Directions for use brochure. www.celtra-Dentsplysirona.com

25. Hallmann L, Ulmer P, Gerngross MD, Jetter J, Mintrone M, Lehmann F, Kern M. Properties of hot-pressed lithium silicate glass-ceramics. Dent Mater 2019; 35: 713-729.

26. Shamseddine L, Motada R, Rifai K, Chidiac JJ. Fit of pressed crowns fabricated from two CAD-CAM wax pattern process plans: A comparative in vitro study. J Prosthet Dent 2017; 118(1):49-54.

27. Beuer F, Schweiger J, Edelhoff D. Digital dentistry: an overview of recent developments for CAD/CAM generated restorations. Br Dent J 2008: 204:505-511.

28. Vojdani M, Torabi K, Farjood E, Khaledi AAR. Comparison of the marginal and internal fit of metal copings cast from wax patterns fabricated by CAD/CAM and conventional wax up techniques. J Dent (Shiraz) 2013; 14(3):118-129.

29. Mclaren EA, Figueira J. Updating classifications of ceramic dental materials: A guide to material selection. Compendium 2015;36(6):739-745.

30. Subasi G, Ozturk N, Inan O, Bozogullari N. Evaluation of marginal fit of two all-ceramic copings withtwo finish lines. Eur J Dent 2012;6:163-168.

31. Zhao K, Wei YR, Pan Y, Zhang XP, Swain MV, Guess PC. Influence of veneer and cyclic loading on failure behavior of lithium disilicate glass-ceramic molar crowns. Dent Mater J 2014;30(2):164-171.

32. Seydler B, Rues S, M“uller D, Schmitter M. In vitro fracture load of monolithic lithiumdisilicate ceramic molar crowns with different wall thicknesses. Clinic Oral Invest 2014;18(4):1165-1171.

33. Dhima M, Carr AB, Salinas TJ, Lohse C, Berglund L, Nan KA. Evaluation of fracture resistance in aqueous environment under dynamic loading of lithium disilicate restorative systems for posterior applications. Part 2. J of Prosthodont 2014;23(5):353-357.

34. Nawafleh N, Hatamleh M, Elshiyab S, Mack F. Lithium disilicate restorations fatigue testing parameters: a systematic review. J of Prosthodont 2016;25(2):116-126.

35. Tribst JPM, De Oliveira Dal Piva AM, Penteado MM, Borges ALS, Bottino MA. Influence of ceramic material, thickness of restoration and cement layer on stress distribution of occlusal veneers. Braz Oral Res 2018;32(e118):1-10.

36. Bosch G, Ender A, Mehl A. Non- and minimally invasive full-mouth rehabilitation of patients with loss of vertical dimension of occlusion using CAD/CAM: an innovative concept demonstrated with a case report. Int. J. Comput. Dent. 2015;18:273-286.

37. Schlichting LH, Resende TH, Reis KR, Magne P. Simplified treatment of severe dental erosion with ultrathin CADCAM composite occlusal veneers and anterior bilaminar veneers. J. Prosthet. Dent. 2016;116:474-482.

38. Albakry M, Guazzato M, Swain MV. Biaxial flexural strength, elastic moduli, and x-ray diffraction characterization of three pressable all-ceramic materials. J Prosthet Dent 2003;89:374-380.

39. Guazzato M, Albakry M, Ringer SP, Swain MV. Strength, fracture toughness and microstructure of a selection of all-ceramic materials. Part I. Pressable and alumina glassinfiltrated ceramics. Dental Mater 2004;20:441-448.

40. Gonzeli R, Kazazoglu E, Ozkan Y. Flexural properties ofleucite and lithium disilicate ceramic materials afterrepeated firing. J Dent Sci 2014;9:144-50.

41. Hallmann L, Ulmer P, Kern M. Effect of microstructure on themechanical properties of lithium silicate glass-ceramics. JMech Behav Biomed Mater 2018;82:355-70.

42. Höland W, Schweiger M, Frank M. A comparison of microstructure and properties of the IPS Empress 2 and theIPS Empress glass ceramics. J Biomed Mater Res2000;53:297-303

43. Höland W. Phenomena and mechanisms of crackpropagation in glass-ceramics. J Mech Behav Biomed Mater2008;1:313-25.

44. Yildiz C, Vanlioglu BA, Evren B, Uludamar A, Kulak-Ozkan Y. Fracture resistance of manually and CAD/CAM manufactured ceramic onlays. J Prosthodont 2013;22:537-42.

45. Krummel A, Garling A, Sasse M, Kern M. Influence of bonding surface and bonding methods on the fracture resistance and survival rate of full-coverage occlusal veneers made from lithium disilicate ceramic after cyclic loading. Dent Mater 2019; 35:1351-1359.

46. Chitmongkolsuk S, Heydecke G, Stappert C. Fracture strength of all-ceramic lithium disilicate and porcelain fused-to-metal bridges for molar replacement after dynamic loading. Eur. J. Prosthodont Restor Dent 2002; 10:15-22. 
47. Ahlers M, Morig G, Blunck U, Hajto J, Probster L, Frankenberger R. Guidelines for the preparation of CAD/CAM ceramic inlays and partial crowns. Int J Comput Dent 2009; 12:309-325.

48. Baig MR, Tan KB, Nicholls JI. Evaluation of the marginal fit of a zirconia ceramic computer-aided machined (CAM) crownsystem. J Prosthet Dent 2010;104:216-227.

49. Pak HS, Han JS, Lee JB, Kim SH, Yang JH. Influence of porcelain veneering on the marginal fit of Digident and Lava CAD/CAM zirconia ceramic crowns. J Adv Prosthodont 2010;2:33-38.

50. Holmes JR, Bayne SC, Holland GA, Sulik WD. Considerations in measurement of marginal fit. J Prosthet Dent 1989;62:405-408.

51. Mounajjed R, Layton DM, Azar B. The marginal fit of E.max Press and E.max CAD lithium disilicate restorations: A critical review. Dent Mater J 2016;35(6):835-844.

52. Wolfart S, Wegner SM, Alhalabi A, Kern M. Clinica;1 evaluation of marginal fit of a new experimental all-ceramic system before and after cementation. Int J Prosthodont 2003;16(6):587-592.

53. Taha D, Spintzyk S, Sabet A, Wahsh M, Salah T. Assessment of marginal adaptation and fracture resistance of endocrown restorations utilizing different machinable blocks subjected to thermomechanical aging. J Esthet Restor Dent 2018;30:319-328.

54. Abduo J, Lyons K, Swain M. Fit of zirconia fixed partial denture: a systematic review. J Oral Rehabil 2010;37:866876.

55. O' Brien WJ, Waxes. Dental materials and their selection. $4^{\text {th }}$ edition. Chicago:Quintessence;2008:272-275.

56. Anusavice KJ, Shen C, Rawls R. Dental waxes, casting investments, and casting procedures. In: Phillips' science of dental materials. $12^{\text {th }}$ edition.St.Louis MO: Saunders; 2014:195-200.

57. Strub JR, Rekow ED, Witkowski S. Computer-aided design and fabrication of dental restorations:current systems and future possibilities. J Am Dent Assoc 2006;13:12891296.

58. Tan PL, Gratton DG, Diaz-Arnold AM, Holmes DC. An in vitro comparison of vertical marginalgaps of CAD/CAM titanium and conventional cast restorations. J Prosthodont 2008; 17:378-383.
59. Abduo J, Lyons K, Bennamoun M. Trends in computeraided manufacturing in prosthodontics: a review of available streams. Int J Dent 2014; Article ID783948:1-15.

60. Conway JR, Emesto CA, Farouki RT, Zhang M. Performance analysis of cross-coupled controllers for $\mathrm{CNC}$ machines based upon precise real-time contour error measurement. Int J Mach Tools Manuf 2012;52:30-39.

61. Dimitrov D, Schreve K, de Beer N. Advances in three dimensional printing state of the art and future prespectives. Rapid Prototyp J 2006;12:136-147.

62. Al Ghazzawi TF, Advancements in CAD/CAM technology: Options for practical implementation. J Prosthodont Res 2016;602:72-84.

63. Zeltner M, Sailer I, Muhlemann S, Ozcan M, Hammerle $\mathrm{CH}$, Benic GI. Randomised controlled within-subject evaluation of digital and conventional workflows for the fabrication of lithium disilicate single crowns. Part 3: marginal and internal fit. J Prosthet Dent 2017;117:354-362.

64. Kirsch C, Ender A, Attin T, Mehl A. trueness of different milling procedures used in dental CAD/CAM systems. Clin Oral Investig 2017;21:551-558.

65. Bosch G, Ender A, Mehl A. A 3-dimensional accuracy analysis of chair side CAD/CAM milling processes. J Prosthet Dent 2014;112:1425-1431.

66. Goujat A, Aboulleil H, Colon P, Jeannin C, Pradelle N, Seux D, Grosgogeat B. Marginal and internal fit of CADCAM inlay/onlay restorations: Asystematic review of in vitro studies. J Prosthet Dent 2019;121:590-597.

67. Cho L, Song H, Koak J et al. Marginal accuracy and fracture strength of ceromer/fiber-reinforced composite crowns: Effect of variations in preparation design. J Prosthet Dent 2002;88(4):388-395.

68. Quintas A, Oliviera F, Bottino M. Vertical marginal discrepancy of ceramic copings with different ceramic materials, finish lines, and luting agents. An in vitro evaluation. J Prosthet Dent 2004;92(3):250-257.

69. Rosentritt M, Sikora M, Behr M, Handel G. In vitro fracture resistance and marginal adaptation of metallic and toothcolored post systems. J Oral Rehabil 2004;31(7):675-681.

70. Blatz MB, Oppes S, Chiche G et al. Influence of cementation technique on fracture strength and leakage of alumina all-ceramic crowns after cyclic loading. Quintessence Int J 2008;39:23-32. 
71. Kim DY, Kim JH, Kim HY, Kim WC. Comparison and evaluation of marginal and internal gaps in cobalt-chromium alloy copings fabricated using subtractive and additive manufacturing. J Prosthodont Res 2018;62:56-64.

72. Alajaji NK, Bardwell D, Finkelman M, Ali A. Micro-CT evaluation of ceramic inlays: comparison of marginal and internal fit of five and three axis CAM systems with a heat press technique. J Esthet Restor Dent 2017;29:49-58.

73. Roperto R, Assaf H, Soares-Porto T, Lang L, Teish S. Are different generations of CAD/CAM milling machines capable to produce restorations with similar quality? J Clin Exp Dent 2016;8:423-428.

74. Sasse M, Krummel A, Klosa K, Kern M. Influence of restoration thickness and dental bonding surface on the fracture resistance of full-coverage occlusal veneers made from lithium disilicate ceramic. Dent Mater. 2015;31:907-15.

75. Baldissara P, Monaco C, Onofri E, Fonseca RG, Ciocca L. Fatigue resistance on monolithic lithium disilicate occlusal veneers: a pilot study. Odontology 2019;107:482-490.

76. Magne P, Carvalho AO, Bruzi G, Giannini M. Fatigue resistance of ultrathin CAD/CAM complete crowns with a simplified cementation process. J Prosthet Dent. 2015;114:574-9

77. Thompson VP, Rekow DE. Dental ceramics and the molar crown testing ground. J Appl Oral Sci. 2004;12:26-36.
78. Ozcan M, Jonasch M. Effect of cyclic fatigue tests on aging and their translational implications for survival of allceramic toothborne single crowns and fixed dental prostheses. J Prosthodont. 2016;27:364-75.

79. Clausen JO, Abou Tara M, Kern M. Dynamic fatigue and fracture resistance of non-retentive all-ceramic full coverage molar restorations. Influence of ceramic material and preparation design. Dent Mater J 2010;26(6):533-538.

80. Pieger S, Salman A, Bidra AS. Clinical outcomes of lithium disilicate single crowns and partial fixed dental prostheses: a systematic review. J Prosthet Dent 2014;112(1):22-30.

81. Rosentritt M, Behr M, Gebhard R, Handel G. Influence of stress simulation parameters on the fracture strength of allceramic fixed-partial dentures. Dent Mater J 2006;22(2):176-182.

82. Ohyama T, Yoshinari M, Oda Y. Effects of cyclic loading on the strength of all-ceramic materials. Int J Prosthodont 1999;12:28-37.

83. Guess PC. Influence of preparation design and ceramic thicknesses on fracture resistance and failure modes of premolar partial coverage restorations. J Prosthet Dent. 2013; 110:264-73.

84. Kikuchi M, Korioth TWP, Hannam AG. The association among occlusal contacts, clenching effort, and bite force distribution in man. J Dent Res 1997;76:1316-25. 